\title{
PERBANDINGAN KEADAAN SOSIAL EKONOMI NELAYAN KELOMPOKDAN MANDIRI DI DESA TATELI WERU KECAMATAN MANDOLANG KABUPATEN MINAHASA PROVINSI SULAWESI UTARA
}

\author{
Gabrila Konore1; Victoria E.N. Manoppo2; Vonne Lumenta² \\ 1)Mahasiswa Fakultas Perikanan dan IImu Kelautan Universitas Sam Ratulangi Manado \\ 2)Staff Pengajar Fakultas Perikanan dan IImu Kelautan Universitas Sam Ratulangi Manado \\ Koresponden email :gabrilakonore@gmail.com
}

\begin{abstract}
The aims of this research to explain and compared the socioeconomic condition of fishermen group and independently in Tateli Weru Village, Mandolang District.This research to add the information and knowledge about socio economic as well as the issue of fisheries developing.

Method to be usedis survey method by using questioner sampling uses is purposive sampling namely fisheries group and independently.

Fishermen in Tateli Weru Village were 105 because all of them lived and activities in coastal closed to mooring boat and fishing equipment. If the fisherman not makes activity, they usually do such as farming, repairing a boat or helpinghis wife. The comparison of two groups were the fisheries group do not go fishing togetheraccordance who needs of each member because the equipment are given by the government but the independly group they fishing depended on climate.
\end{abstract}

Keywords: Socioeconomic, fishermen group, independently group

\begin{abstract}
Abstrak
Penelitian ini bertujuan untuk menjelaskan dan membandingkan keadaan sosial ekonomi nelayan kelompok dan mandiri di Desa Tateli Weru Kecamatan Mandolang, menambah informasi dan pengetahuan mengenai keadaan sosial ekonomi nelayan kelompok dan mandiri selain itu sebagai hal-hal yang dapat menjadi bahan untuk membangun perikanan melalui pekerjaan peneliti di kemudian hari.

Metode Penelitian menggunakan metode survei, yaitu berupa pertanyaan-pertanyaan terstruktur berupa kuisioner.Pengambilan sampel menggunakan metode purposive sampling yaitu nelayan yang tergabung dalam kelompok dan mandiri.

Nelayan yang ada di Desa Tateli Weru berjumlah 105 orang nelayan karena suatu kelompok masyarakat yang kehidupannya berada di pesisir pantai dan mata pencahariannya tergantung pada aktivitas penangkapan ikan di laut, serta pemukiman berada di pesisir pantai yang dekat dengan tambatan perahu dan peralatan tangkap. Peralatan kelengkapan yang dibawa responden untuk melaut berupa jerigen bensin, dayung, jangkar, serok.Jika responden tidak melakukan aktivitas melaut, mereka biasanya melakukan aktivitas lain, seperti bertani, memperbaiki perahu, dan ada yang membantu istri.Jika dilihat dari kelompok nelayan, mereka tidak pergi menangkap ikan secara bersama-sama, hanya peralatan yang diberikan pemerintah digunakan sesuai dengan keperluan dari setiap anggota, jadi para anggota bergantian menggunakan alat tersebut.
\end{abstract}

Kata kunci: Sosial ekonomi, nelayan kelompok, nelayan mandiri

\section{PENDAHULUAN}

Sektor Kelautan dan Perikanan menjadi salah satu program prioritas pembangunan daerah, guna mewujudkan kedaulatan pangan dalam menunjang berbagai sektor pembangunan. Hal ini tentunya sangat realistis karena Sulawesi Utara memiliki potensi sumberdaya kemaritiman yang sangat besar serta memiliki desa pantai yang dijadikan sebagai aspek ekonomi yang menunjang kehidupan masyarkat khususnya masyarakat nelayan.

$$
\text { Provinsi Sulawesi Utara }
$$

merupakan salah satu daerah yang mempunyai nelayan yang cukup signifikan salah satunya yaitu Desa Tateli Weru dengan sebagian penduduk bermata pencaharian sebagai nelayan berjumlah 105 orang.

Kecamatan Mandolang terletak di Kabupaten Minahasa, Provinsi Sulawesi 
Utara, memiliki 12 desa, tetapi hanya 6 desa saja yang sebagian masyarakat berprofesi sebagai nelayan, yaitu: Kalasey, Tateli 1, Tateli 2, Tateli 3, Tateli Weru, Koha . Di Kecamatan Mandolang ada juga nelayan yang dalam usahanya bersifat kelompok dan mandiri, keduanya mempunyai karakteristik yamg berbeda dari segi sosial dan ekonomi. Dari 6 desa tersebut Desa Tateli Weru yang menjadi lokasi penelitian, karena desa ini jumlah nelayan banyak dan kelompok nelayan masih aktif.

\section{METODE PENELITIAN}

\begin{tabular}{ccc} 
Metode & \multicolumn{2}{c}{ penelitian ini } \\
menggunakan & metode survei dan \\
pengumpulan & data (kuesioner,
\end{tabular}
wawancara dan sebagainya), penelitian ini dilakukan untuk menjelaskan, dan membandingkan keadaan sosial ekonomi nelayan kelompok dan mandiri di Desa Tateli Weru Kecamatan Mandolang Kabupaten Minahasa Provinsi Sulawesi Utara.

Pengambilan

sampel

menggunakan metode purposive sampling untuk mendapatkan sampel jenis nelayan yang ikut dalam kelompok dan nelayan mandiri yang ada di Desa Tateli Weru Kecamatan Madolang Kabupaten Minahasa.Sampel nelayan mandiri hanya diambil sebanyak 10-15\% dari populasi karena jumlah nelayan mandiri yang ada di Tateli Weru Kecamatan Mandolang Kabupaten Minahasa berjumlah 105 orang.Menurut Sugiyono (2008) sampel adalah sebagian dari jumlah dan karakteristik yang dimiliki oleh populasi tersebut.

Tahapan-tahapan pengambilan data nelayan kelompok dan nelayan mandiri yang ada di Desa Tateli Weru Kecamatan Mandolang :

1. Mendata jumlah nelayan, yaitu 105 orang
2. Berdasarkan jumlah nelayan 105 orang, didapatkan hasil bahwa nelayan yang tergabung dalam kelompok yaitu 26 orang dan hanya 1 kelompok yang aktiv dari 3 kelompok yang ada, yaitu kelompok sejahtera dengan jumlah nelayan 10 orang.

3. Jumlah nelayan yang tidak tergabung dalam kelompok yaitu 76 orang , tetapi hanya 10 orang saja yang masih tergabung dalam kelompok dan masih aktiv. Jadi 105$10=95$ orang.

Selanjutnya menggunakan teori Arikunto yang mengatakan, jika subjeknya besar dapat diambil antara $10-15 \%$ atau $20-55 \%$ atau lebih tergantung sedikit banyaknya dari :

1. Kemampuan peneliti dilihat dari waktu, tenaga dan dana

2. Sempit luasnya wilayah pengamatan dari setiap subyek, karena hal ini menyangkut banyak sedikitnya dana

3. Besar kecilnya resiko yang ditanggung oleh peneliti untuk peneliti yang resikonya besar, tentu saja tidak samplenya besar hasilnya akan lebih baik.

Jadi, sampel yang diambil untuk nelayan mandiri $10 \% \times 95=9,5$ dibulatkan menjadi 10 orang, Jumlah responden yaitu 20 orang dengan 10 nelayan kelompok dan 10 mandiri.

\section{HASIL DAN PEMBAHASAN}

\section{Nelayan Kelompok}

Berdasarkan hasil penelitian kelompok nelayan yang masih aktif di Desa Tateli Weru sampai saat ini pernah mendapat bantuan yaitu kelompok sejahtera, dan semua anggota kelompok sejahtera yang menjadi responden. Kelompok sejahtera dibentuk pada tahun 2017 dengan proses pembentukan 
anggota kelompok maupun ketua kelompok ditentukan langsung oleh Hukum Tua Desa Tateli Weru dengan jumlah personil 10 orang dan diketuai oleh Bapak Patras Lukas, bantuan yang pernah didapatkan yaitu 2 motor tempel, bantuan tersebut didapatkan dari Kementerian Kelautan dan Perikanan Sulawesi Utara dan kantornya berada di Kalasey dan juga berdasarkan wawancara dengan ketua kelompok ternyata mereka secara kelompok tidak pernah pergi melaut bersama-sama, jadi bantuan yang didapatkan dipakai secara bergantian, tergantung dari anggota yang membutuhkan alat tersebut.

\section{Nelayan Mandiri}

Nelayan mandiri didesa Tateli Weru yang menjadi responden yaitu menggunakan alat tangkap serta perahu sendiri, bahkan ada yang membuat perahu milik pribadi, nelayan mandiri selain berprofesi sebagai nelayan merekapun memiliki aktivitas lain ketika tidak melaut, mereka: bertani maupun membuka usaha kecil-kecilan seperti warung. Tetapi ada juga yang hanya membuat perahu ketika tidak melaut, bahkan ada yang hanya membantu pekerjaan istri di rumah. Kehidupan nelayan tentunya bergantung penuh di laut, jadi jika cuaca tidak baik maka responden yang ada akan mencari profesi lain yang menghasilkan uang.

\section{Keadaan Umum Nelayan Secara Sosial}

Keadaan sosial dan ekonomi nelayan baik secara kelompok maupun mandiri tentunya tidak sama, memiliki perbedaan masing-masing dan ada beberapa variabel yang menunjukkan keadaan sosial ekonomi baik nelayan kelompok maupun mandiri.

\section{Tingkat Pendidikan}

Pendidikan merupakan salah satu aspek sosial yang penting untuk menunjang manusia dalam mengembangkan usahanya dan memudahkan seseorang agar semakin maju dalam keterampilan berusaha.Pendidikan mempengaruhi kemampuan seseorang dalam menyerap teknologi baru seperti modernisasi alat tangkap ikan.Perbandingan tingkat pendidikan antara kelompok nelayan dan nelayan mandiri dapat dilihat pada Tabel 1.

Tabel 1. Perbandingan Jumlah Nelayan Berdasarkan Tingkat Pendidikan

\begin{tabular}{|c|l|c|c|c|c|}
\hline \multirow{2}{*}{ No } & \multirow{2}{*}{ Pendidikan } & \multicolumn{2}{|c|}{ Kelompok } & \multicolumn{2}{c|}{ Mandiri } \\
\cline { 2 - 5 } & & Jumlah & $\mathbf{( \% )}$ & Jumlah & $(\mathbf{\%})$ \\
\hline 1 & SD & 8 & $80 \%$ & 6 & $60 \%$ \\
\hline 2 & SMP & 2 & $20 \%$ & 2 & $20 \%$ \\
\hline 3 & SMA & - & - & 1 & $10 \%$ \\
\hline 4 & S1/Sederajat & - & - & 1 & $10 \%$ \\
\hline
\end{tabular}

Sumber : Pengolahan data Primer, 2018

Berdasarkan Tabel 1, tingkat pendidikan antara nelayan kelompok dan mandiri yang paling banyak tingkat pendidikan SD dengan jumlah 8 orang untuk nelayan kelompok atau berdasarkan persentase $80 \%$ dan untuk mandiri 6 orang dengan persentase $60 \%$, yang paling sedikit tingkat pendidikan SMA dan S1 dan untuk nelayan kelompok tidak ada yang lulusan SMA dan S1, dapat dikatakan bahwa pendidikan yang paling tinggi yaitu nelayan mandiri.

\section{Umur}

Umur juga merupakan salah satu faktor sosial yang dapat menentukan nelayan dalam melakukan suatu penangkapan. Karena semakin bertambah umur maka kekuatan dalam menangkap ikan akan semakin berkurang. Perbandingan tingkat umur antara kelompok nelayan dan nelayan mandiri dapat dilihat pada Tabel 2. 
Tabel 2. Jumlah Nelayan Berdasarkan Umur

\begin{tabular}{|c|l|c|c|c|c|}
\hline $\mathbf{N}$ & & \multicolumn{2}{|c|}{ Kelompok } & \multicolumn{2}{c|}{ Mandiri } \\
\cline { 2 - 6 } $\mathbf{0}$ & Umur & Jumlah & $\mathbf{( \% )}$ & Jumlah & $\mathbf{( \% )}$ \\
\hline 1 & $15-46$ & 7 & $70 \%$ & 5 & $50 \%$ \\
\hline 2 & $56-65$ & 3 & $30 \%$ & 4 & $40 \%$ \\
\hline 3 & $>65$ & - & - & 1 & $10 \%$ \\
\hline
\end{tabular}

Sumber : Pengolahan data Primer, 2018

Berdasarkan Tabel 2 tingkat umur antara kelompok nelayan dan mandiri yang paling banyak yaitu umur 15-46 dengan persentase $70 \%$ untuk nelayan kelompok dan untuk mandiri $50 \%$ yang paling sedikit responden yang berumur $>65$ hanya 1 orang saja dalam nelayan mandiri atau berdasarkan persentase $5 \%$.

\section{Agama}

Dilihat dari segi sosial responden yang ada di Desa Tateli Weru mayoritas beragama Kristen Protestan. Dalam kelompok nelayan ada juga yang beragama muslim, tetapi antara sesama kelompok nelayan adanya saling menghormati dan menghargai satu sama lain. Kegiatan sosial yang diikuti oleh responden baik mandiri maupun kelompok yaitu aktivitas keagamaan seperti ibadah kolom, dan pada hari minggu responden tidak melakukan aktivitas melaut, karena mereka memprioritaskan hari minggu untuk beribadah di Gereja.

\section{Suku}

Selain itu dapat dilihat dari segi sosial yaitu suku responden, kelompok etnis atau suku yang setiap anggotanya mengidentifikasikan dirinya dengan sesamanya, biasanya berdasarkan garis keturunan yang sama. Identitas suku ditandai oleh pengakuan dari orang lain atas ciri khas tersebut seperti kesamaan budaya, bahasa, agama, dan perilaku.Berdasarkan hasil wawancara suku responden dapat dilihat pada Tabel 3.
Tabel 3. Jumlah Nelayan Berdasarkan Suku

\begin{tabular}{|c|c|c|c|c|c|}
\hline \multirow{2}{*}{ No } & \multirow{2}{*}{ Suku } & \multicolumn{2}{|c|}{ Kelompok } & \multicolumn{2}{c|}{ Mandiri } \\
\cline { 3 - 6 } & & Jumlah & $(\%)$ & Jumlah & $(\%)$ \\
\hline 1 & Minahasa & - & - & 2 & $20 \%$ \\
\hline 2 & Sangihe & 10 & $100 \%$ & 8 & $80 \%$ \\
\hline
\end{tabular}

Berdasarkan Tabel 3 dapat dilihat bahwa etnis dari kelompok berasal dari suku Sangihe berjumlah 10 orang $(100 \%)$ nelayan sedangkan mandiri yang paling banyak berasal dari suku Sangihe $80 \%$, sedangkan suku Minahasa hanya 2 orang saja dan berdasarkan persentase yaitu $20 \%$. Walaupun ada yang berbeda secara suku atau etnis tetapi tidak membuat responden antara satu dengan yang lain kehilangan solidaritas, justru mereka tetap saling menghargai dan menghormati satu sama lain. Hasil wawancara dengan responden yang tergabung dalam kelompok nelayan semuanya berasal dari daerah yang sama yaitu Sangihe. Jadi lebih mudah menjalin komunikasi antara sesama anggota, sedangkan yang 1 orang dari Minahasa responden tersebut tidak tergabung dalam kelompok tetapi hanya sebagai nelayan mandiri saja.

\section{Tanggungan Keluarga}

Jumlah tanggungan keluarga adalah banyaknya anggota keluarga yang terdiri dari istri, dan anak, serta orang lain yang turut serta dalam keluarga berada atau hidup dalam satu rumah dan makan bersama yang menjadi tanggungan kepala keluarga. Tanggungan keluarga dapat dilihat pada Tabel 4 berikut.

Tabel 4. Jumlah Nelayan Berdasarkan Jumlah Tanggungan Keluarga

\begin{tabular}{|c|c|c|c|c|c|}
\hline \multirow{2}{*}{ No } & \multirow{2}{*}{$\begin{array}{c}\text { Jumlah } \\
\text { Tanggungan } \\
\text { Keluarga }\end{array}$} & \multicolumn{2}{|c|}{ Kelompok } & \multicolumn{2}{|c|}{ Mandiri } \\
\hline & & Jumlah & $(\%)$ & Jumlah & $(\%)$ \\
\hline 1 & $1-2$ & 2 & 20 & 3 & 30 \\
\hline 2 & $3-5$ & 6 & 60 & 5 & 50 \\
\hline 3 & $>5$ & 2 & 20 & 2 & 20 \\
\hline
\end{tabular}

Sumber : Pengolahan Data Primer, 2018 
Berdasarkan Tabel 4 dapat dilihat bahwa jumlah tanggungan keluarga baik nelayan kelompok maupun mandiri yang paling banyak berjumlah 3-5 tanggungan yaitu $60 \%$ untuk nelayan kelompok dan $50 \%$ nelayan mandiri, dan jumlah tanggungan keluarga yang lebih dari 5 orang hanya mendapatkan presentase $20 \%$ baik nelayan dalam kelompok maupun nelayan mandiri. Ternyata Jumlah tanggungan keluarga nelayan kelompok dan mandiri sama, akan tetapi letak perbedaan antara nelayan kelompok dan mandiri dilihat dari tanggunggan keluarga yaitu nelayan kelompok yang $>5$ mereka merasa terbebani, karena pendapatan yang mereka miliki tidak terlalu banyak, sedangkan nelayan mandiri mereka merasa mampu atau merasa tidak terbebani karena mereka mempunyai pendapatan yang cukup, selain itu nelayan mandiri juga memiliki tabungan.

\section{Kegiatan Sosial yang Diikuti}

Kegiatan sosial adalah suatu kegiatan yang dilakukan oleh seseorang atau kelompok untuk menyalurkan kepeduliannya, di Desa Tateli Weru ada beberapa kegiatan sosial yang diikuti seperti kerja bakti, arisan, selain itu kegiatan sosial, keagamaan, hari ulang tahun, perkawinan dan kedukaan. Masyarakat nelayan yang ada di Desa Tateli Weru memiliki kepedulian sosial yang tinggi, ketika ada acara ulang tahun, perkawinan, maupun kedukaan.Masyarakat nelayan ikut membantu keluarga yang membuat acara seperti memasang tenda, maupun menyiapkan makanan.
Tabel 5. Jumlah Nelayan Berdasarkan Kegiatan Sosial yang Diikuti

\begin{tabular}{|c|c|c|c|c|c|}
\hline $\mathbf{N}$ & Keg. Sosial & \multicolumn{2}{|c|}{ Kelompok } & \multicolumn{2}{c|}{ Mandiri } \\
\cline { 3 - 6 } $\mathbf{0}$ & yang diikuti & Jumlah & $\mathbf{( \% )}$ & Jumlah & $(\mathbf{\% )}$ \\
\hline 1 & Kerja Bakti & 10 & 100 & 4 & 40 \\
\hline 2 & Arisan & - & - & 8 & 80 \\
\hline 3 & Keagamaan & 10 & 100 & 10 & 100 \\
\hline
\end{tabular}

Sumber: Pengolahan Data Primer, 2018

Berdasarkan Tabel 5, dapat dilihat bahwa keadaan sosial yang diikuti baik nelayan kelompok maupun mandiri berbeda, kerja bakti yang diikuti nelayan kelompok terletak dalam kegiatan sosial seperti kerja untuk nelayan kelompok mereka pergi kerja bakti bersama-sama dan wajib mengikuti kerja bakti karena mengingat nelayan kelompok mendapat bantuan dari hukum tua, dan kerja bakti merupakan program desa, sedangkan nelayan mandiri sesuka hati. Untuk kegiatan sosial dilihat dari arisan nelayan mandiri mengikuti arisan, sedangkan untuk nelayan kelompok tidak mengikuti arisan, karena mengingat pendapatan nelayan kelompok tidak banyak.Untuk Keagamaan baik nelayan kelompok maunpun mandiri mengikuti ibadah seperti ibadah kolom dan pada hari minggu nelayan yang beragama Kristen tidak pergi melaut karena mereka mengutamakan ibadah di gereja.

\section{Keadaan Umum Nelayan Secara Ekonomi}

Ekonomi merupakan hal yang sangat diperlukan dalam kehidupan manusia, secara ekonomi responden yang ada di Desa Tateli Weru menggantungkan hidupnya di laut dan secara umum didominasi oleh kaum lakilaki yang menyandang predikat sebagai kepala rumah tangga, dalam memulai suatu usaha khususnya di bidang penangkapan ikan memerlukan modal untuk membeli peralatan menangkap ikan di laut. Hasil wawancara dengan responden baik secara kelompok 
maupun mandiri modal yang didapat berbeda satu sama lain, jika mereka membentuk kelompok maka tujuannya yaitu untuk mendapatkan bantuan dari pemerintah berupa alat tangkap. Berdasarkan hasil wawancara perbedaan modal awal responden baik secara kelompok maupun mandiri dapat dilihat pada Tabel 6.

Tabel 6. Pemberian Bantuan Berdasarkan Modal Awal

\begin{tabular}{|c|l|l|}
\hline No & \multicolumn{1}{|c|}{ Kelompok } & \multicolumn{1}{c|}{ Mandiri } \\
\hline 1 & Pemerintah & Sendiri \\
\hline 2 & $\begin{array}{l}\text { Kementerian Kelautan } \\
\text { Perikanan }\end{array}$ & Pekerjaan sampingan \\
\hline 3 & $\begin{array}{l}\text { Motor tempel 2 buah } \\
\text { didapat dari KKP }\end{array}$ & $\begin{array}{l}\text { Membuat Perahu } \\
\text { Sendiri }\end{array}$ \\
\hline
\end{tabular}

Sumber : Pengolahan data Primer, 2018

Dilihat dari Tabel 6, menjelaskan bahwa modal awal yang didapatkan oleh nelayan dalam kelompok yaitu dari pemerintah oleh kementerian kelautan perikanan dan biasanya diurus oleh hukum tua yang ada di Desa Tateli weru. Bantuan yang pernah didapat berupa motor tempel 2 buah dan dari nelayan mandiri modal awal yaitu modal sendiri dari pekerjaan sampingan, selain itu ada yang membuat perahu sendiri, bahkan ada yang memiliki usaha sendiri seperti membuka warung kecil-kecilan.

\section{Pendapatan}

Nelayan di Desa Tateli Weru merupakan kepala rumah tangga dalam keluarga, jadi wajib bagi mereka untuk mencari nafkah dalam rangka pemenuhan kebutuhan hidup setiap hari, pekerjaan sebagai nelayan memang tidaklah mudah karena jika dilihat dari segi pendapatan terkadang tinggi tetapi terkadang rendah, hal ini dikarenakan cuaca yang tidak baik atau cuaca buruk, seperti ombak keras serta angin kencang, tentunya masyarakat nelayan tidak akan pergi melaut, karena jika mereka melaut tentunya akan mengalami resiko yang tinggi. Jadi jika mereka tidak melaut nelayan yang ada di Desa Tateli Weru harus mencari pekerjaan lain agar mendapatkan penghasilan, jadi jika mereka tidak melaut para nelayan yang ada di Desa Tateli Weru juga memiliki perkerjaan sampingan seperti bertani, buruh/tukang, ojek, bahkan ada yang memiliki usaha seperti warung kecil-kecilan.

Tabel 7. Jumlah Nelayan Berdasarkan Pendapatan

\begin{tabular}{|c|c|c|c|c|c|}
\hline $\mathbf{N}$ & \multirow{2}{*}{$\mathbf{0}$} & Pendapatan (Rp) & \multicolumn{2}{|c|}{ Kelompok } & \multicolumn{2}{|c|}{ Mandiri } \\
\cline { 3 - 6 } & & Jlh & $\mathbf{( \% )}$ & Jlh & $(\%)$ \\
\hline 1 & $<500$ & 6 & 60 & - & - \\
\hline 2 & $500.00-1.000 .000$ & 4 & 40 & 10 & 100 \\
\hline
\end{tabular}

Sumber : Pengolahan Data Primer, 2018

Berdasarkan hasil penelitian didapat hasil pendapatan nelayan kelompok berbeda dengan pendapatan nelayan mandiri, hal ini disebabkan oleh:

1. Kepemilikan alat, nelayan mandiri dan nelayan kelompok memiliki kepemilikan alat yang berbeda-beda, nelayan mandiri memiliki alat tangkap sendiri, sedangkan nelayan kelompok sering bergantian dalam pemakaian alat tangkap, sistem kelompok sejahtera yang ada di Desa Tateli Weru bantuan yang didapat dari pemerintah dipakai secara bergantian, tergantung siapa yang membutuhkan.

2. Waktu, jika nelayan kelompok pergi melaut hanya 1 hari, karena bantuan yang diberikan Pemerintah kepada kelompok harus digunakan secara bergantian, sedangkan nelayan mandiri pergi melaut biasanya 3-5 hari

Jika dilihat dari persamaan antara nelayan kelompok dan mandiri samasama menggunakan pendapatan untuk kebutuhan keluarga setiap hari. Berdasarkan hasil analisis statistik uji $\mathrm{t}$ didapat hasil pendapatan nelayan mandiri berbeda nyata dengan pendapatan nelayan kelompok 
$(p<0,05)$,signifikansi ini menunjukkan pendapatan nelayan mandiri lebih tinggi dibandingkan nelayan kelompok.

\section{Pengeluaran}

Jika dilihat dari kebutuhan rumah tangga baik nelayan kelompok maupun mandiri ternyata sama, keduanya mengeluarkan biaya untuk makanminum per hari yaitu sekitar Rp 100.000Rp 200.000 dan untuk bayar tagihan, seperti air per bulan Rp 100.000 tergantung pemakaian dan untuk air $\mathrm{Rp}$ 25.000 per bulan. Sedangkan pengeluaran untuk beli pakaian dapat dilihat pada Tabel 8.

Tabel 8. Jumlah Nelayan Berdasarkan Pengeluaran (Beli Pakaian)

\begin{tabular}{|c|c|c|c|c|c|}
\hline No & $\begin{array}{c}\text { Kebutuhan Rumah } \\
\text { Tangga }\end{array}$ & \multicolumn{2}{|c|}{ Kelompok } & \multicolumn{2}{c|}{ Mandiri } \\
\cline { 3 - 6 } & & Jlh & $\mathbf{( \% )}$ & Jlh & $\mathbf{( \% )}$ \\
\hline 1. & 1 kali/tahun (hari raya) & 7 & $70 \%$ & 6 & $60 \%$ \\
\hline 2. & $2-4$ kali/tahun & 2 & $20 \%$ & 3 & $30 \%$ \\
\hline 3. & $>5$ kali/tahun & 1 & $10 \%$ & 1 & $10 \%$ \\
\hline
\end{tabular}

Sumber : Hasil Pengolahan Data Primer, 2018

Berdasarkan Tabel 8 pengeluaran nelayan mandiri maupun nelayan kelompok tidak berbeda atau sama karena responden paling banyak membeli pakaian 1 tahun 1 kali hanya hari raya saja seperti Natal atau Idul Fitri, tetapi ada juga responden yang membeli pakaian sesuai kebutuhan jika sudah sobek atau tidak layak pakai maka akan segera dibeli.

\section{Tabungan}

Tabungan sangat berguna bagi responden, karena dengan menabung ketika ada keadaan darurat, maka responden tidak perlu meminjam uang, tabungan juga sebagai simpanan pokok untuk hari tua nanti ataupun di masa yang akan datang, dengan menabung artinya kita menghemat.
Tabel 9. Jumlah Nelayan yang Menabung

\begin{tabular}{|c|c|c|c|c|c|}
\hline \multirow{2}{*}{ No } & \multirow{2}{*}{ Tabungan } & \multicolumn{2}{|c|}{ Kelompok } & \multicolumn{2}{c|}{ Mandiri } \\
\cline { 3 - 6 } & & Jumlah & $\mathbf{( \% )}$ & Jumlah & $\mathbf{( \% )}$ \\
\hline 1 & Tidak ada & 4 & 40 & 4 & 40 \\
\hline 2 & Ada & 6 & 60 & 6 & 60 \\
\hline
\end{tabular}

Sumber : Pengolahan data primer (2018)

Berdasarkan hasil penelitian tabungan nelayan kelompok tidak berbeda atau sama dengan tabungan nelayan mandiri, hal ini menunjukkan bahwa baik kelompok maupun mandiri memiliki uang simpanan yang sama, artinya jika ada sisa uang maka mereka akan menyimpan uang tersebut untuk keperluan yang lebih penting nantinya. Perbedaan tabungan antara nelayan kelompok dan mandiri yaitu nelayan kelompok menyimpan uang sendiri, sedangkan nelayan mandiri mereka menyimpan uang di bank. Berdasarkan hasil analisis statistik uji t didapat hasil tabungan nelayan mandiri tidak berbeda atau sama dengan tabungan nelayan dalam kelompok $(p>0,05)$, Signifikansi ini menunjukkan bahwa baik kelompok maupun mandiri memiliki uang simpanan yang sama, artinya jika ada sisa uang maka mereka akan menyimpan uang tersebut untuk keperluan yang lebih penting nantinya.

\section{Kondisi Rumah}

Rumah sangat penting bagi kehidupan keluarga karena rumah merupakan tempat berteduh dan tempat melakukan aktivitas setiap hari. Jika rumah layak untuk ditempati maka keluargapun akan merasa nyaman untuk tinggal di dalam rumah itu sendiri. Kondisi rumah responden dapat dilihat pada Tabel 10.

Tabel 10. Jumlah Nelayan Berdasarkan Kondisi Rumah

\begin{tabular}{|c|l|c|c|c|c|}
\hline \multirow{2}{*}{ No } & \multicolumn{1}{|c|}{$\begin{array}{l}\text { Kondisi } \\
\text { Rumah }\end{array}$} & \multicolumn{2}{|c|}{ Kelompok } & \multicolumn{2}{c|}{ Mandiri } \\
\cline { 3 - 6 } & Jumlah & $(\%)$ & Jumlah & $(\%)$ \\
\hline 1. & Permanen & 2 & 20 & 5 & 50 \\
\hline 2. & $\begin{array}{l}\text { Semi } \\
\text { Permanen }\end{array}$ & 8 & 80 & 4 & 40 \\
\hline 3. & Papan & - & - & 1 & 10 \\
\hline
\end{tabular}

Sumber : Pengolahan Data Primer, 2018 


\section{Berdasarkan hasil penelitian} kondisi rumah antara nelayan kelompok dan mandiri sama, ini menunjukkan baik kelompok maupun mandiri memiliki jenis rumah yang hampir tidak berbeda, tetapi walaupun masih ada masyarakat dalam kelompok yang kondisi rumah dan toiletnya memprihatinkan. Misalnya kondisi rumah ketua kelompok (bapak Patras Lukas), dapat dilihat pada Gambar 1.

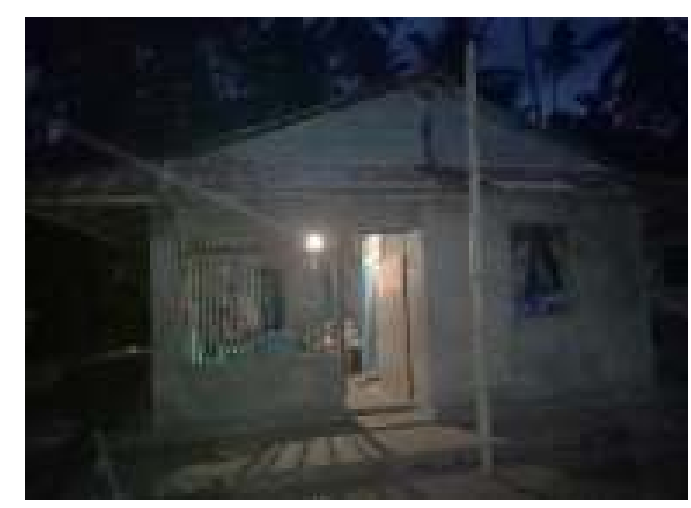

Gambar 1. Salah Satu Kondisi Rumah Nelayan Kelompok

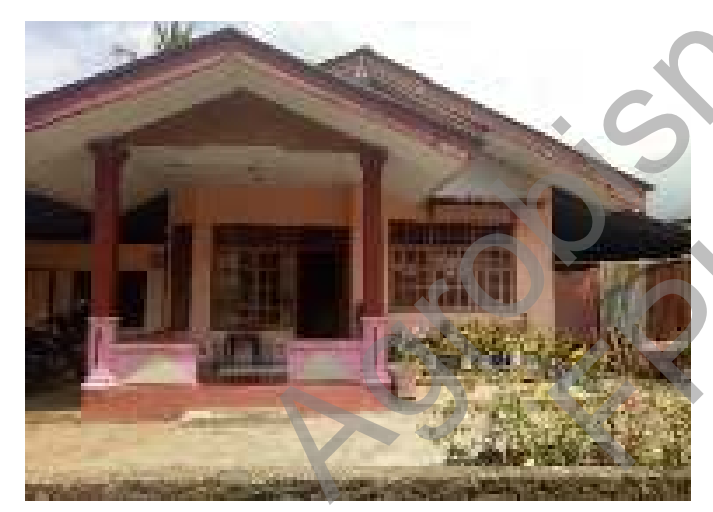

Gambar 2. Salah Satu Kondisi Rumah Nelayan Mandiri

Berdasarkan hasil analisis statistik uji $t$ didapat hasil bahwa kondisi rumah antara nelayan mandiri dengan nelayan dalam kelompok tidak berbeda atau sama $(p>0,05)$.

\section{KESIMPULAN}

Keadaan sosial dan ekonomi nelayan kelompok dan mandiri, dilihat dari segi sosial dari nelayan kelompok dan mandiri memiliki sikap saling menghargai antara sesama nelayan, tetapi sikap solidaritas hanya nelayan kelompok yang memilikinya dikarenakan nelayan mandiri hanya mengatur diri sendiri sedangkan nelayan kelompok secara bersama-sama, tingkat pendidikan nelayan kelompok dan mandiri yang paling banyak tingkat pendidikan SD yang paling sedikit tingkat pendidikan SMA dan S1. Tingkat umur antara nelayan kelompok dan mandiri yang paling banyak yaitu umur 15-46, dan yang paling sedikit responden yang berumur $>65$ hanya 1 orang saja dalam nelayan mandiri, dan untuk nelayan kelompok tidak ada yang berumur $>65$ tahun.

Segi ekonomi nelayan kelompok terdiri dari 10 orang dan alat tangkap yang mereka gunakan secara bergantian untuk itu secara ekonomi nelayan kelompok masih rendah dibandingkan nelayan mandiri, hal ini dikarenakan nelayan kelompok pergi melaut tidak tergantung waktu tetapi tergantung bantuan dari pemerintah, karena bantuan yang didapat digunakan secara bergantian, tergantung dari anggota yang membutuhkan alat tersebut, jadi nelayan kelompok tidak setiap hari melaut, sedangkan nelayan mandiri melaut sesuka hati, karena alat tangkap yang mereka pakai adalah alat tangkap sendiri, dan secara ekonomi akan berpengaruh, karena ketika nelayan kelompok tidak melaut, maka pemasukan keuanganpun sedikit dibandingkan nelayan mandiri, tabungan antara nelayan kelompok dan mandiri yaitu nelayan kelompok menyimpan 
uang sendiri, sedangkan nelayan mandiri mereka menyimpan uang di bank.

\section{DAFTAR PUSTAKA}

Anonimous. 1997. Undang-Undang RI Nomor 23 Tahun 1997 tentang Pengelolaan Lingkungan Hidup.

Basrowi dan Siti Juariyah. 2010. Analisis Kondisi Sosial Ekonomi dan Tingkat Pendidikan Masyarakat Desa Srigtading, Kecamatan Labuhan Maringgai, Kabupaten Lampung Timur. Jurnal Ekonomi dan Pendidikan. Vol. 7 No. 1 April 2010.

Bengen, D. 2002. Sinopsis Ekosistem dan Sumberdaya Alam Pesisir dan Laut Serta Prinsip Pengelolaanya. PKSPL-IPB: Bogor.

Castells, M. 2004. The Network Society A Crosscultural Perspective. Cheltenham, UK Nirthampton, MA, USA: Edward Elgar Publishing. Inc.

Hadi, S. 2000. Metodologi Penelitian. Yogyakarta: Andi Yogyakarta.

Kusnadi. 2004. Polemik Kemiskinan Nelayan, Bantul: Pondok Edukasi \& Pokja Pembaruan.

Kusnadi. 2006. Filosofi Pemberdayaan Pesisir, Bandung: Humaniora.

Kusnadi. 2009. Keberdayaan Nelayan Dalam Dinamika Ekonomi Pesisir. Yogyakarta: ArRuzz Media.

Moleong L.J., 2005. Metode Penelitian Kualitatif, Bandung, Edisi Revisi, Penerbit PT. Remaja Rosdakarya.

Mubyarto.2002. Pemberdayaan Ekonomi Rakyat dan Peranan IImu-IImu Sosial. Yogyakarta

Muchtar. 2014. Menyusun Business Plan \& Rencana Aksi. Cetakan Pertama. Bandung: Yrama Widya.

Muhibbinsyah. 2003. Psikologi Belajar, Jakarta : PT Raja Grafindo.
Narimawati, U. 2008. Metodologi Penelitian Kuantitatif dan Kualitatif, Teori dan Aplikasi. Bandung: Agung Media.

Robbins. 2000. Ketrampilan Dasar. PT. Raja Grafindo. Jakarta.

Salim, A. 2001.Teori dan Paradigma Penelitian Sosial: Buku Sumber Untuk Penelitian Kualitatif (edisi kedua, Agustus 2006), Tiara.

Satria. 2004. Pengantar Sosiologi Masyarakat Pesisir, Jakarta : Pustaka Cisendo.di Ruang Anyelir RSUD Arifin Achmad Provinsi Riau.

Sekaran, U. 2011. Metode Penelitian Untuk Bisnis. Jakarta: Salemba Empat.

Subri, M. 2005. Ekonomi Kelautan. Jakarta : Raja Grafindo Persada.

Sugiyono. 2010. Metode Penelitian Kuantitatif Kualitatif \& RND. Bandung: Alfabeta.

Suhardjo, D. 2007. Arti Penting Pendidikan Mitgasi Bencana dalam Mengurangi Resiko Bencana, Yogyakarta : Universitas Islam Indonesia Yogyakarta Press.

Supardi. M. D., 2006 Metode Penelitian Mataram: Yayasan Cerdas Press.

Undang-Undang Nomor 45 Tahun 2009 tentang Perubahan atas Undang-Undang Nomor 31 Tahun 2004 tentang Perikanan.

Walgito.B., 2010.Bimbingan dan Konseling (Studi \&Karir). Yogyakarta: Penerbit CV. Andi Offset.

Widodo, J. 2006. Pengelolaan Sumberdaya Perikanan Laut, Gadjah Mada University Press.

Wignyosoebroto, S. 2005. Desentralisasi dalam Tata Pemerintahan Kolonial Hindia - Belanda: Kebijakan dan Upaya Sepanjang Babak Akhir Kekuasaan Kolonial di Indonesia (1900-1940). Malang: Bayumedia Publishing.

Winarno. S. 1986. Pengantar Interaksi Belajar Mengajar dan Teknik Metode Mengajar. Bandung: Tarsito. 
PS. Agrobisnis Perikanan FPIK UNSRAT

AKULTURASI

Available online :http://ejournal.unsrat.ac.id/index.php/akulturasi

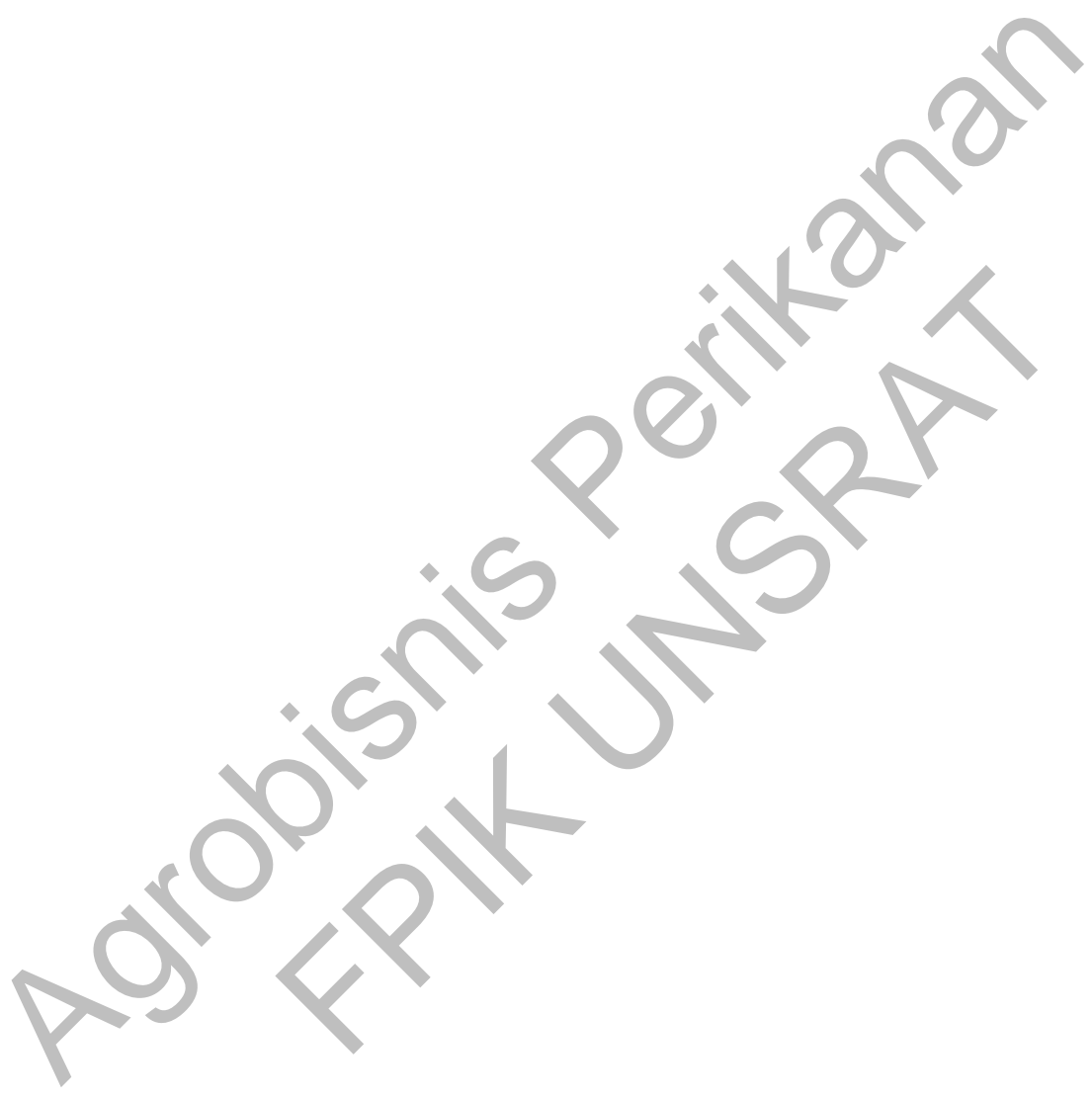

